\title{
Evitación de daños del oldo en la compactación del hormigón con mesas vibratorias
}

E. FAUER, Dipl. Ing. Escuela de Ingeniería de la Construcción. APOLIDA

Baustoffindustrie n.o 5, (octubre 1973), pág: 15 y sgts.

La dificultad de oír provocada por la intensa acción del ruido de larga duración, es actualmente una de las enfermedades profesionales más frecuentes en la República Democrática de Alemania. Para evitar su propagación se han creado especialmente para la industria de la construcción y de materiales de construcción en el año 1966 bases legales, en las que se han declarado obligatorias las prescripciones de la TGL 10687 . Entretanto se ha perfeccionado este estándar. Las innovaciones más importantes para la industria de materiales de construcción consisten en el procedimiento de medida diferente y en el nivel de ruido permisible que resulta. El medidor de nivel de ruido por impulsos que se utiliza para la medida del ruido debe ajustarse también a la valoración de frecuencia A y a la valoración de tiempo I (ruido de impulso) cuando se desea medir el ruido perjudicial para el ó́do. El nivel de presión sonora, con un efecto de ruido ininterrumpido $(>5 \mathrm{~h}$ durante un turno de trabajo), no debe superar el valor de $90 \mathrm{~dB}$ (AI) (hasta ahora $\mathrm{N} \mathrm{85)}$

\section{El ruido en la industria del hormigón}

Los requisitos mínimos prescritos legalmente no se observan en muchas fábricas de hormigón de la República Democrática de Alemania. Aproximadamente el $34 \%$ de los empleados están espuestos a un nivel de ruido comprendido entre 105 y $115 \mathrm{~dB}$ (AI). Si se trata de un ruido permanente, al cabo de un prolongado período de tiempo hay que esperar en ellos, con bastante seguridad, daños del oído interno, en tanto no se tomen contramedidas eficaces. El elevado nivel sonoro se provoca sobre todo por los aparatos de compactación, especialmente por las mesas de vibración. Al desconectar todos los aparatos de compactación, el nivel sonoro producido por las restantes máquinas muchas veces es inferior a 80 dB (AI). En grandes fábricas de hormigón las mesas vibratorias, sin embargo, están funcionando constantemente a plena carga en las instalaciones de mezcla y transporte; es frecuente que domine un ruido permanente. Como medida más eficaz se han mostrado las caperuzas protectoras contra el ruido. Mediante estas caperuzas el nivel de ruido se ha reducido de tal forma que satisface la disposiciones legales. Los inconvenientes de esta posibilidad consisten, por una parte, en los costes de adquisición relativamente elevados de las 
caperuzas y en el gran espacio requerido. Ademảs, se producen pérdidas de trabajo al colocar y desmontar las caperuzas. Frecuentemente se argumenta también con que las caperuzas impiden la observación del proceso de compactación.

\section{Evitación de daños del oído mediante acción intermitente del ruido}

Si todas las mesas vibratorias de ruido intensivo se acoplan de tal manera en una nave de fábrica que puedan conectarse y desconectarse simultáneamente, el tiempo de acción productora de ruido corresponde a la duración de la compactación.

Si el nivel sonoro de los demás equipos entre dos procesos de compactación alcanza $<80$ dB (AI), existe entonces una pausa de ruido. Un cambio periódico de esta clase entre el tiempo de producción de ruido y la pausa del mismo significa una acción de ruido intermitente. El estándar TGL 10687 permite en este caso niveles de ruido considerablemente superiores. Durante el plazo de silencio el oído interno del ser humano expuesto al ruido se recupera de tal manera que no se producen daños permanentes en el oído. 